\title{
DETERMINATION OF PCDD/FS AND DIOXIN-LIKE PCBs IN CHINESE COMMERCIAL PCBS AND EMISSIONS FROM A TESTING PCB INCINERATOR
}

\author{
Ke Jiang, Lingjun Li, Yudong Chen, Jun Jin \\ Research Center for Fco-Environmental Sciences, Chinese Academy of Science, Beijing 100085, P.R.
}

China

\begin{abstract}
Large amounts of polychlorinated biphenyls (PCBs) had been produced in China. In order to dispose of them appropriately, a set of experimental PCB incinerators have been manufactured in China. The 2,3,7,8-substituted toxic polychlorinated dibenzodioxins and furans (PCDD/Fs) congeners in stack ash and bottom ash samples from the incinerator and technical products \# IPCB and \#2PCB (for the reason of comparison) were measured. In addition, the levels of these toxic congeners were converted to $2,3,7,8$ TCDD TEQ. Moreover, levels of dioxin-like PCB congeners and 2,3,7,8-TCDD TEQ values in two types of commercial PCBs products and stack ash were determined.

(C) 1997 Elsevier Science Ltd. All rights reserved
\end{abstract}

\section{INTRODUCTION}

Polychlorinated biphenyls (PCBs) are synthetic chemicals which are resistant to degradation in nature. Their long-time persistence and high bioaccumulation potential through the food chain resulted in the contamination of PCBs in every component of the global ecosystem. Approximately eight thousand tons of PCBs were produced in China during the 1960's and 1970's. The typical models of Chinese commercial PCBs are \#1 PCB (the chlorine content is $42 \%$, which is similar to Aroclor 1242) and \#2PCB (the chlorine content is $56 \%$, which is similar to Aroclor 1254) ${ }^{[1]}$ Most of these PCBs products were used as dielectric fluid in electronic capacitors, and a small part of which were used as additives in paints. 
Many electronic capacitors containing PCBs have been considered as solid wastes since the 1980's. According to our investigation, a large number of the capacitors are domestic. There are also some imported capacitors and transformers. The content of PCBs in capacitor soaker fluid exceeds $90 \%$. The concentration of PCBs in some transformer oils attains $50 \% .{ }^{[2]}$ If the temporarily stored wastes containing high concentration of PCBs are released into the environment, it is likely to cause serious contamination, which is harmful to the eco-environment and human health. An experimental incinerator is designed and manufactured to destroy wastes of high PCBs concentration. During the experimental period, emissions from the incinerator wcre monitored in order to select the optimal operating conditions, resulting in high destruction efficiency and minimum formation of toxic substances.

The total contents of residual PCBs and the concentration of tetra through octa PCB homologues in the emissions from different parts of the incinerator have been determined under different operating conditions. Considering the fact that the toxicity of PCBs congeners is related to the substitution pattern of chlorine atoms, it was found that non-ortho substituted or only one or two chlorine atoms in ortho position show a dioxin-like toxicity. The evaluation of PCBs environmental toxicity depends mostly on the analysis of dioxin-like PCBs. In this paper, the levels of dioxin-like PCB congeners and their 2,3,7,8-TCDD toxic equivalents (TEQ) values in two types of commercial PCBs products and stack ash samples were provided. In addition, the 2,3,7,8-substituted toxic polychlorinated dibenzodioxins and furans (PCDD/Fs) congeners in the technical products \#1PCB and \#2PCB (for the reason of comparison), stack ash and bottom ash samples have been quantified and reported as 2,3,7,8-TCDD TEQ.

The destruction efficiency of high concentration PCBs in this incinerator can be higher than 99.9999\%. With the TEQ value of $217 \mathrm{ng} \mathrm{TEQ} / \mathrm{g}$ in the technical product \#1PCB, the TEQ value of residual dioxins in a stack ash sample and a bottom ash sample are reduced to $47.2 \mathrm{ng} \mathrm{TEQ} / \mathrm{g}$ and $87.9 \mathrm{pg}$ $\mathrm{TEQ} / \mathrm{g}$, respectively. The determination results of dioxin-like PCBs in the stack ash sample from PCBs incinerators showed that the content and toxicity of dioxin-like PCBs diminished 20000 and 50000 times respectively after incineration.

\section{EXPERIMENTAL}

\section{Information of the incinerator:}

Type: The first chamber: fixed bed combustor;

The second chamber: gas purified combustor.

Total volume: $1 \mathrm{~m}^{3}$ 
Temperature: the first chamber: $700-1100 \mathrm{C}$;

the second chamber: $1200-1400 \mathrm{C}$.

Feeding: semi-continuous type for solid waste $30-60 \mathrm{~kg} / \mathrm{h}$; continuous type for liquid waste: 15 $\mathrm{kg} / \mathrm{h}$.

Flue gas treatment: cooling and removing $\mathrm{HCl}$ by introducing alkali aqueous solution.

Chimney height: $15 \mathrm{~m}$

The quantity of stack gas: $300-600 \mathrm{Nm}^{3} / \mathrm{h}, 1200-1300 \mathrm{Nm}^{3} / \mathrm{h}$ (after injection and adding gas)

The content of $\mathrm{O}$, in flue gas: $5-10 \%(\mathrm{v} / \mathrm{v})$

Gas retention time: about 2 seconds

The quantity of emission water: 2.5 tons/h

\section{Sampling}

(1) Raw material for incineration: Chinese technical PCBs products collected from discarded capacitors manufactured in Xi'an Chemical Factory, China. \#1 PCB contains $42 \%$ chlorine, which is similar to Aroclor 1242, \#2 PCB contains 53\% chlorine, which is similar to Aroclor 1254.

(2) Bottom ash was obtained from the chamber of the incinerator.

(3) Stack ash was scraped from the in wall of the incinerator chimney.

(4) Modified gas sampling method 5 of USEPA ${ }^{[3]}$ were used to collect fly ash and stack gas samples.

(5) Waste water had been used to wash exhaust gas of the incinerator.

\section{Extraction and clean up}

USEPA Method $1613^{[4]}$ was modified to treat the PCBs technical products and stack ash samples from PCBs incinerator before HRGC/HRMS analysis. The stack ash sample was digested with $3 \mathrm{M} \mathrm{HCl}$, followed by Soxhlet extraction with toluene. For the analysis of PCDD/Fs, nine ${ }^{13} \mathrm{C}-\mathrm{PCDD} / \mathrm{Fs}$ standards were used to spike the sample before extraction. The extracted sample solution was applied onto the acid/base silica column and basic alumina column. $3 \% \mathrm{CH}_{2} \mathrm{Cl}_{2} /$ hexane solution was used to elute the sample from the acid/base silica column. $2 \% \mathrm{CH}_{2} \mathrm{Cl}_{2} /$ hexane and $50 \% \mathrm{CH}_{2} \mathrm{Cl}_{2} /$ hexane were used to elute the basic alumina column. PCDD/Fs and dioxin-like PCBs were collected in the last fraction of elution (50\% $\mathrm{CH}_{2} \mathrm{Cl}_{2} /$ hexane mixed solvent).

\section{Quantification}

(1) Total contents of PCBs were determined by GC/ECD and GC/MS, and calculated by Webb method. ${ }^{[5]}$

(2) PCB homologue.

A known amount of ${ }^{13} \mathrm{C}$-labeled tri- through deca- chlorobiphenyls surrogates were spiked into the sample, and the sample was extracted and cleaned up by the above methods for HRGC/MS analysis.

(3) PCDD/Fs analysis. 
According to the reference method by Environment Canada ${ }^{[6]}$ the sample was spiked with a surrogate standard mixture of ${ }^{13} \mathrm{C}$-labeled $\mathrm{PCDD} / \mathrm{Fs}$ congeners. The spiked sample was extracted and cleaned up for HRGC/HRMS/SIM analysis. $30 \mathrm{~m} \times 0.32 \mathrm{~mm}$ (i.d.) DB-5 capillary column was used. $1 \mathrm{ng}$ ${ }^{13} \mathrm{C}-1,2,3,4-\mathrm{TCDD}$ and ${ }^{13} \mathrm{C}-1,2,3,7,8,9-\mathrm{HxCDD}$ were added right before HRGC/HRMS analysis to determine internal standard recovery. Seventeen 2,3,7,8-substituted PCDD/PCDF congeners were quantified.

(4) Dioxin-like PCBs.

The same sample pretreatment method was used for the extraction of dioxin-like PCBs congeners. The sample extract was analyzed by HRGC/MS and quantified using the external standard method. Coplanar PCB congener standards PCB77, PCB123, PCB118, PCB114, PCB105, PCB126, PCB167, PCB 156 and PCB 169 were provided by Environment Canada.

\section{RESULTS AND DISCUSSIONS}

The content of PCBs in the stack gas (and fly ash) from domestic experimental PCBs incinerators was 3$60 \mathrm{ng} / \mathrm{l}$, the PCBs concentration in waste water was less than $0.3 \mathrm{ppb}$, and the level of the residual PCBs in the bottom ash ranged from 1 to $25 \mathrm{ppm}$. It is confirmed that the destruction efficiency of high concentration PCBs in this experimental incinerator attains $99.9999 \%$. The total amount of residual PCBs in the stack ash is $51 \mathrm{ppm}$. It can be concluded that the toxicity from PCBs in stack ash was diminished about 100,000 times compared to the technical product \#1 PCB.

Since most of the PCBs' environmental toxicity is contributed by the dioxin-like PCBs congeners, ${ }^{[7]}$ the study of destruction of dioxin-like PCBs after incineration treatment is of speciat interest. The levels of nine dioxin-like PCB congeners in \#1PCB, \#2PCB and stack ash samples are provided in Table 1. Their toxicity is reported as $2,3,7,8$-TCDD TEQ value. From the data in Table 1 , the major toxicity of the incineration material \#1PCB is due to the significantly high level of PCB77 and PCB105, the total TEQ value is $2.097 \mathrm{ug} / \mathrm{g}$. With slightly higher TEQ value, more kinds of dioxin-like PCBs congeners are presented in \#2PCB. With similar congener patterns in stack ash samples as in technical product \#1 PCB, both of the total content of dioxin-like PCBs and total TEQ value decreased dramatically after incineration. According to our calculation, the content of dioxin-like PCBs and the toxicity in stack ash is diminished 20000 and 50000 times, respectively. 


\begin{tabular}{|c|c|c|c|c|c|}
\hline \multicolumn{6}{|c|}{ in \#1 PCB, \#2 PCB and stack ash } \\
\hline PCB congeners & IUPAC No. & TEFs & \#1 PCB (ug/g) & \#2 PCB (ug/g) & stack ash $(\mathrm{ng} / \mathrm{g})$ \\
\hline $3,3^{\prime}, 4,4^{\prime}-$-TCB & 77 & 0.0005 & 2098 & 149 & 40 \\
\hline $2^{\prime}, 3,4,4^{\prime}, 5--\mathrm{PeCB}$ & 123 & 0.0001 & 2.63 & 59.7 & ND \\
\hline $2,3,4,4,5--\mathrm{PeCB}$ & 118 & 0.0001 & ND & ND & ND \\
\hline $2,3,4,4,5-\mathrm{PeCB}$ & 114 & 0.0005 & ND & ND & ND \\
\hline $2,3,3^{\prime}, 4,4^{\prime}-$-.PeCB & 105 & 0.0001 & 482 & 6529 & 20 \\
\hline $3,3^{\prime}, 4,4^{\prime}, 5-\mathrm{-PeCB}$ & 126 & 0.1 & 10 & 20.9 & ND \\
\hline $2,3^{\prime}, 4,4^{\prime}, 5,5^{\prime}--\mathrm{HxCB}$ & 167 & 0.00001 & ND & ND & ND \\
\hline $2,3,3,4,4,5--\mathrm{HxCB}$ & 156 & 0.0005 & ND & 11.8 & ND \\
\hline $3,3^{\prime}, 4,4^{\prime}, 5,5^{\prime}--\mathrm{HxCB}$ & 169 & 0.01 & ND & ND & ND \\
\hline \multicolumn{2}{|l|}{ total dioxin-like PCBs } & & 2593 & 6761 & 60 \\
\hline total TEQ & & & 2.097 & 2.829 & 0.022 \\
\hline
\end{tabular}

Figure 1 through Figure 5 are the high resolution mass chromatogram for tetra- through octa$\mathrm{CDD} / \mathrm{Fs}$. For all the sample analyses, ${ }^{13} \mathrm{C}$-labeled internal standards were added to confirm the existence of the specific congener and ensure the accurate quantification.

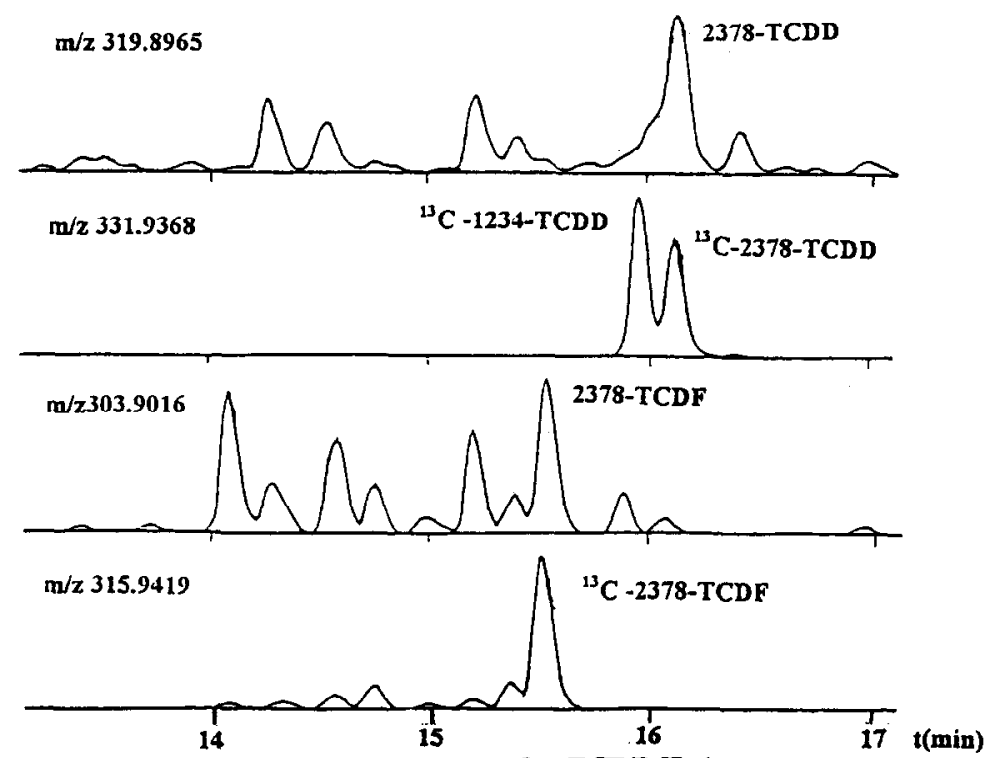

Figure 1. The high resolution mass chromatogram for TCDD/Fs in stack ash. 


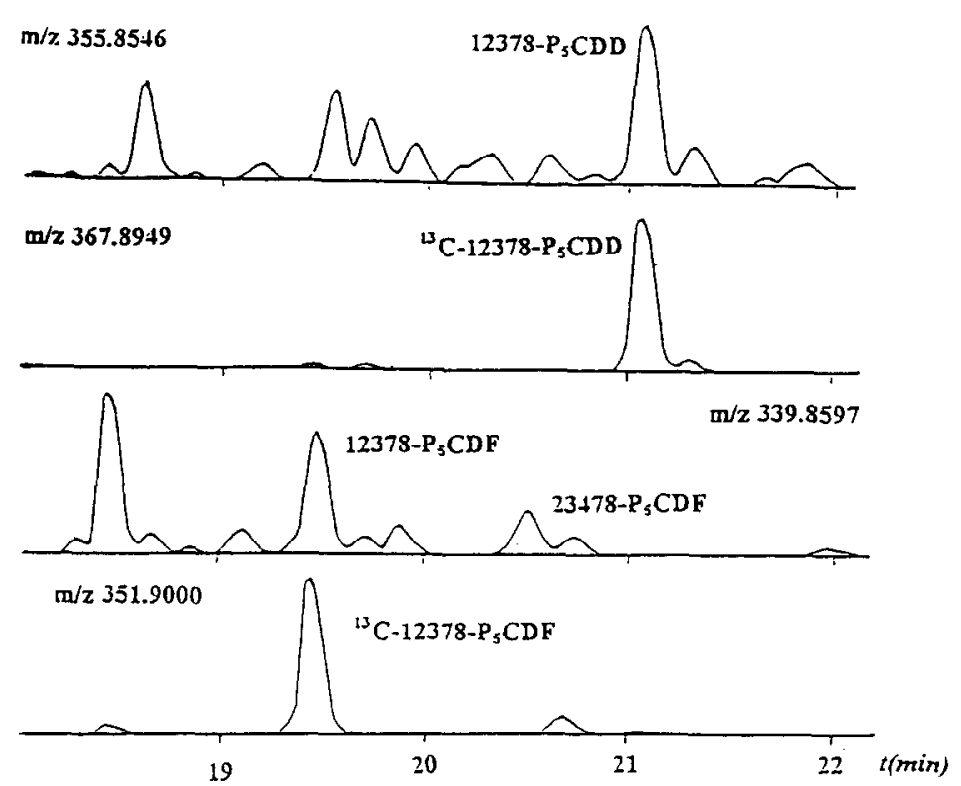

Figure 2. The high resolution mass chromatogram for $\mathrm{P}_{5} \mathrm{CDD} / \mathrm{Fs}$ in stack ash.

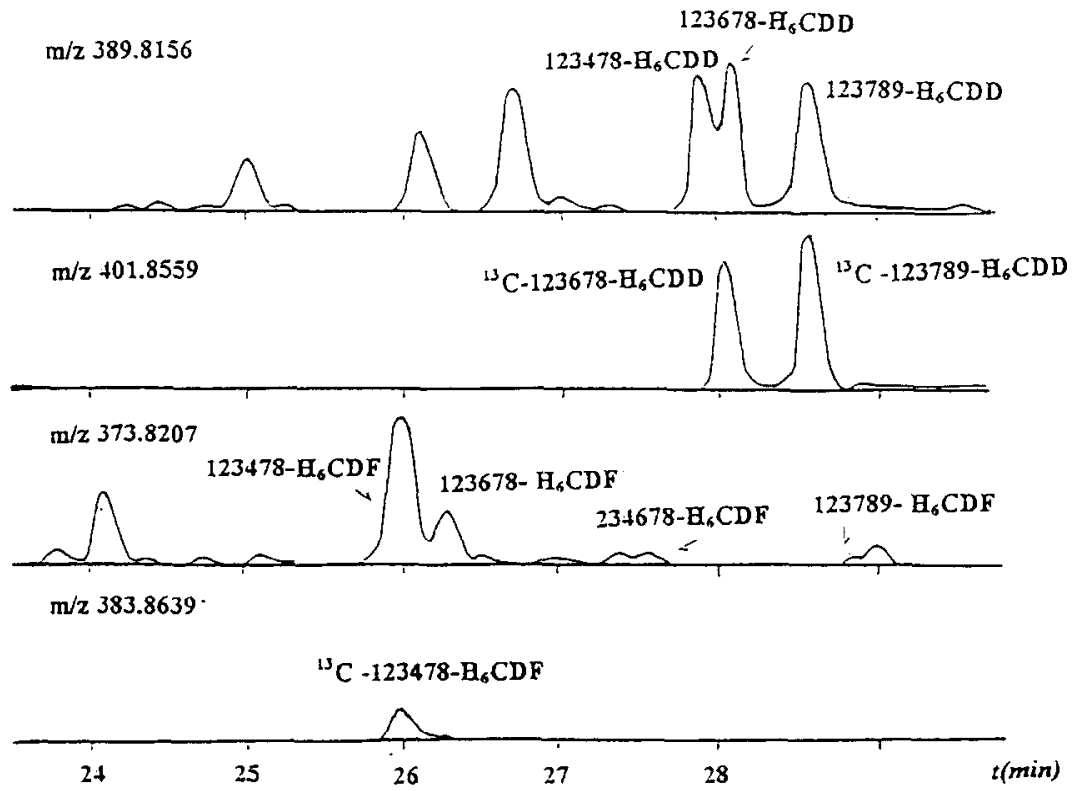

Figure 3. The high resolution mass chromatogram for $\mathrm{H}_{6} \mathrm{CDD} / \mathrm{Fs}$ in stack ash. 


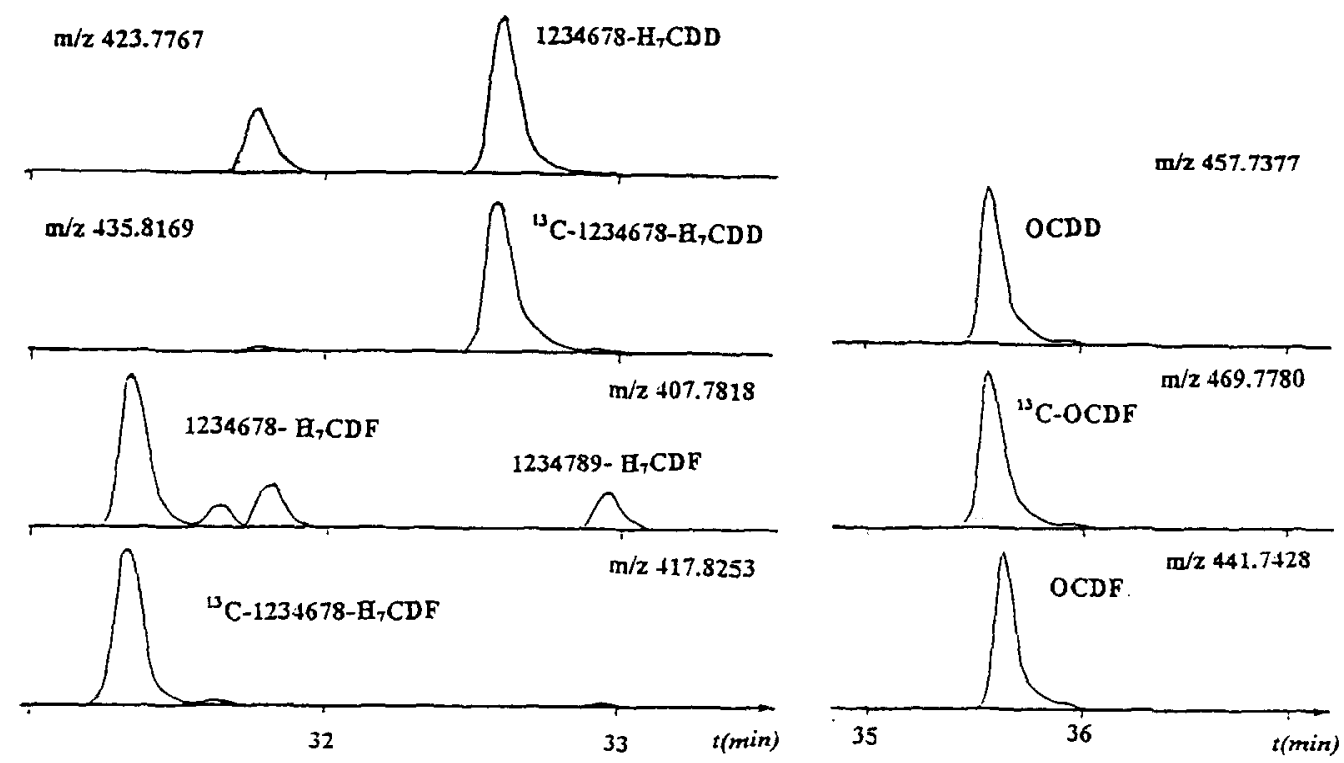

Figure 4. The high resolution mass chromatogram for $\mathrm{H}_{7} \mathrm{CDD} / \mathrm{Fs}$ in stack ash.

Figure 5. The high resolution mass chromatogram for $O C D D / F s$ in stack ash.

Table 2 presents congener-specific PCDD/F analytical results and calculated 2,3,7,8-TCDD TEQ values for raw materials Chinese commercial \#1PCB, stack ash and bottom ash samples from the incinerator. Data of \#2PCB is also provided for comparison.

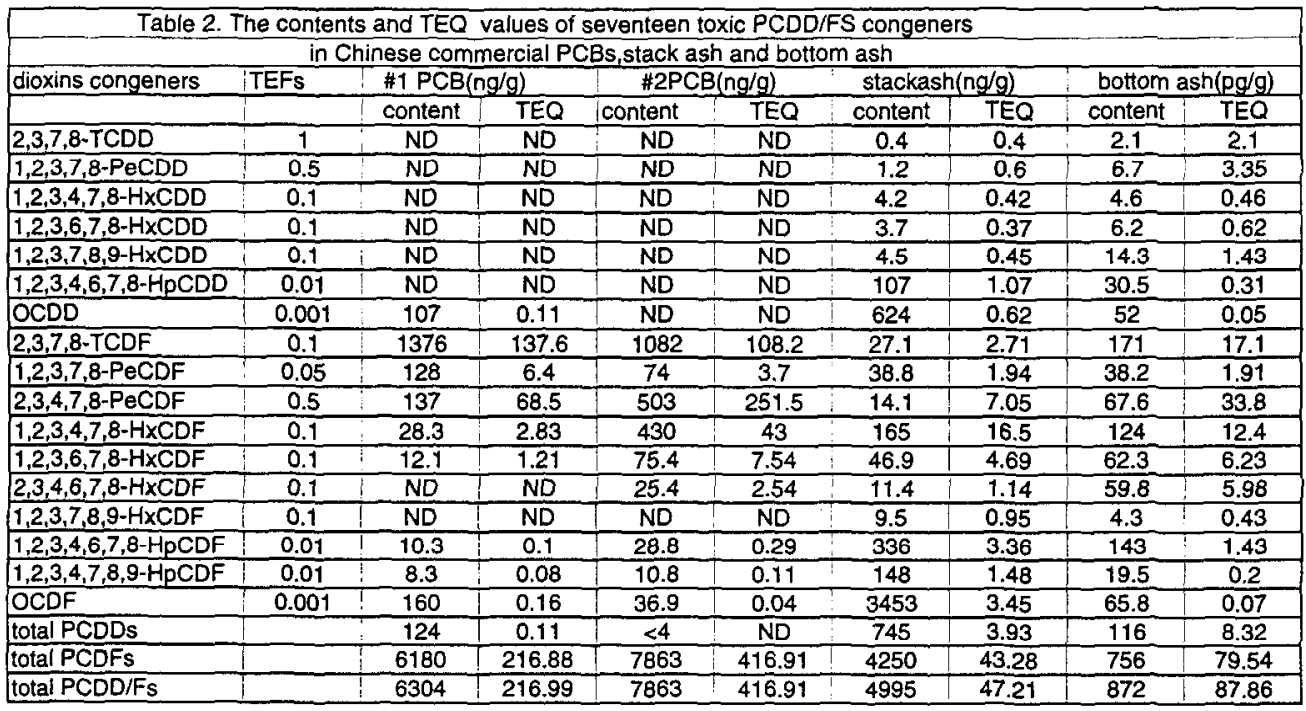


Based on Table 2, nost of the TEQ toxicity of PCBs samples is contributed by the elevated levels of PCDFs. Only very low level of OCDD was detected in \#1PCB, whereas the high level of PCDFs resulted in TEQ value of $217 \mathrm{ng} / \mathrm{g}$. No dioxins were detected in \#2PCB, but elevated levels of PCDFs congeners generated $417 \mathrm{ng} \mathrm{TEQ} / \mathrm{g}$. Both stack ash and bottom ash samples contained small amount of dioxins, which were formed during incineration. However, the more toxic PCDF congeners such as $2,3,7,8-\mathrm{TCDF}$ and $2,3,4,7,8-\mathrm{PeCDF}$ reduced significantly.

Figure 6 illustrated the homologue profile of PCDD/Fs in Chinese technical product \#1PCB and stack ash samples. This profile is quite different from municipal waste incineration. For municipal incineration emission, generally the furan level is high for tetra and penta homologues and decreases progressively toward OCDF. Stack ashes from PCB incineration, however, normally have low level of dioxins but higher level of furans that increase with the increment of substituted chlorine atoms from tetra to octa homologue.

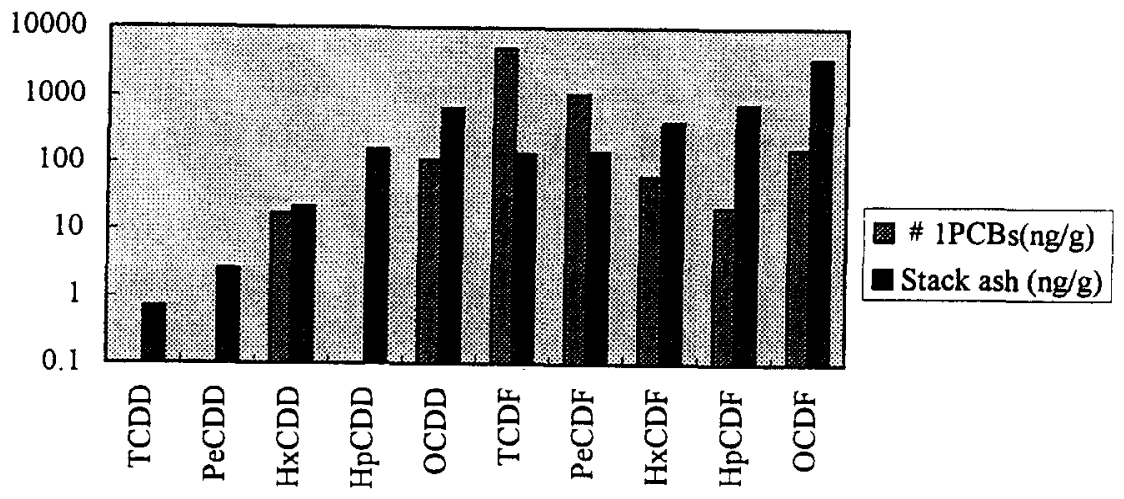

Figure 6. Homologues Distribution of PCDD/Fs for Stack ash and Chinese \# 1PCBs

2,3,7,8-substituted congener-specific PCDD/Fs pattern of \#1PCB, stack ash and bottom ash samples are shown in Figure 7. Significant high levels of TCDF through HxCDF congeners, contribute to most of the TEQ value of \#1PCB. After the incineration, all seventeen 2,3,7,8-substituted PCDD/Fs congeners were detected in the stack ash and bottom ash samples. However, the TEQ values reduced greatly in the ash samples. Quantitative results are provided in Table 2.

Compared with technical product \#1PCB, the TEQ value of $87.9 \mathrm{pg} / \mathrm{g}$ in the bottom ash is 2500 times lower, which demonstrates the effectiveness of the PCB incinerator. The TEQ value of stack ash is $47.2 \mathrm{ng} / \mathrm{g}$, whose toxicity is less than that of technical product \#1 PCB. Because this TEQ value is higher than the USEPA criterion (1ppb TEQ), it is suggested that the emissions such as stack ash from the 
experimental PCBs incinerator should be handled more carefully. Further study to optimize the operating conditions of the PCB incinerator is necessary.

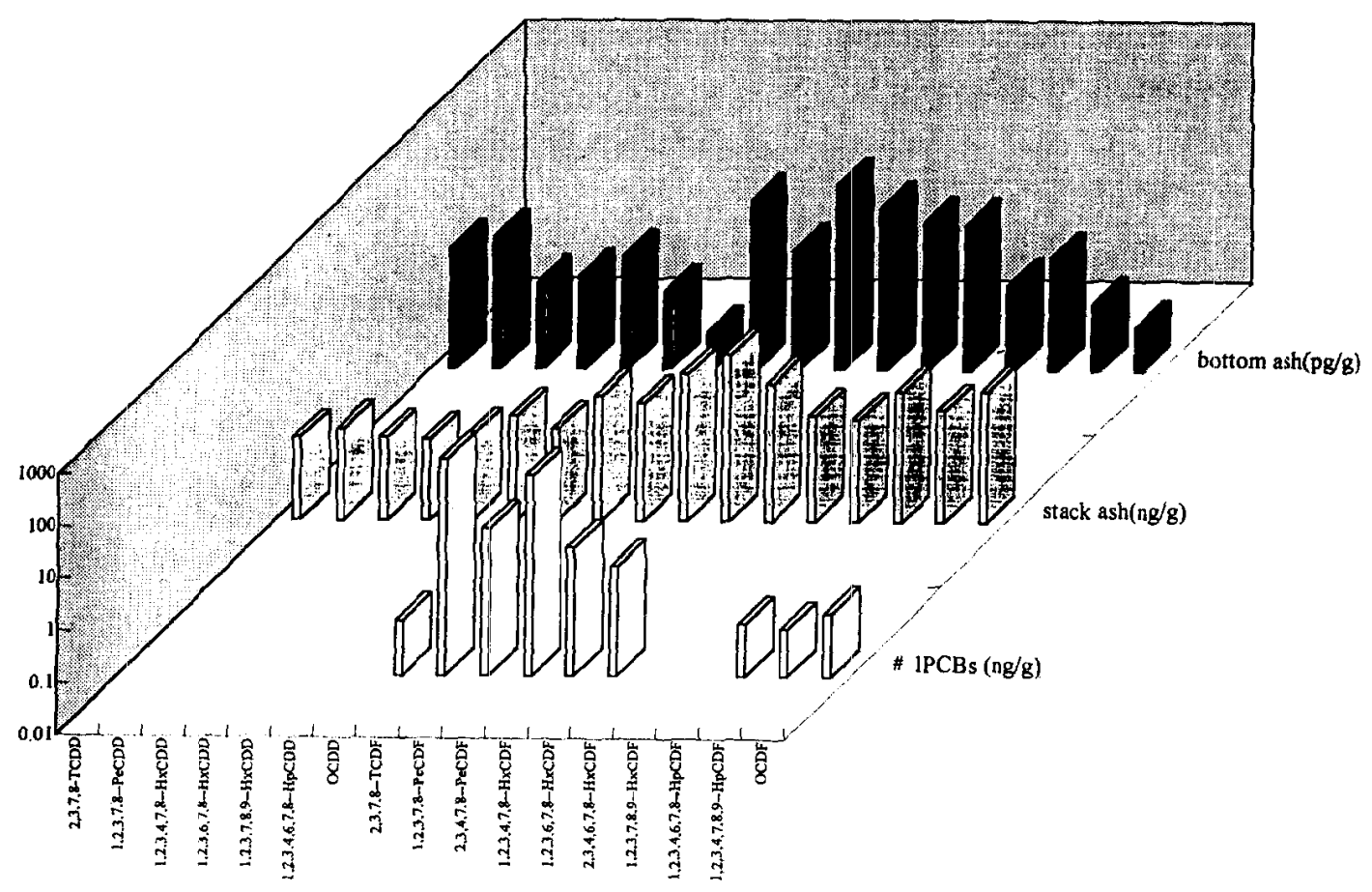

Figure 7. PCDD/Fs profile of \#1PCB, stack ash and bottom ash samples

\section{ACKNOWLEDGMENT}

The authors acknowledge the assistance of the River Road Environmental Technology, Environment Canada for HRGC/HRMS analysis. 
950

\section{REFERENCES}

[1] Ke Jiang, Rongli Chen, Jide Wang, Zhiquan Kang and Yaming Bian, Environmental analysis of polychlorinated biphenyls by GC/MS --Use of Chinese commercial products as references, Chin. J. Anal. Chem. 10, $711-715$ (1982).

[2] Lingjun Li, Jimao Wu, Yudong Chen and Ke Jiang, Determination of polychlorinated biphenyls in transformer oils, Chin. J. Environ. Sci, 14, 69-72 (1993).

[3] USEPA, Modified Method 5 Sampling train, 560/5-83-004, 1986

[4] USEPA, Method 1613, Revision A, 1990

[5] R.G. Webb, A.C Mc Call, Quantitative PCB standards for electron capture gas chromatography, J. Chromatogr. Sci., 11, 366-373 (1973).

[6] Environment Canada, Report, EPS, 1/RM/19, 1992

[7] U.G. Ahlborg, G.C. Backing, L.S. Birnbaum, A. Brouwer, HJ Derks, M. Feeley, G. Golor, A. Ilanberg, J. C. Larsen, A.K.D. Liem, S.H. Safe, C. Schlatter, F. Warn, M. Younes, E. Yrjanheikki, Toxic equivalency factors for dioxin-like PCBs, Chemosphere, 28, 1049-1067 (1994).

[8] F.W. Karasek and Otto Hutzinger, Incineration, Anal. Chem., 58, 633A-642A (1986). 